\title{
Idiopathic Dilated Cardiomyopathy: Clinical Profile of 100 Patients
}

\author{
Sajal K. Banerjee1, Fazlur Rahman¹, Mohammad Salman², Md. Abu Siddique1, SM Mustafa Zaman¹, Khairul \\ Anam ${ }^{1}$, Mukhlesur Rahman ${ }^{1}$, Md. Khurshed Ahmed ${ }^{1}$, MA Rasheed ${ }^{3}$, Nargis Akhter ${ }^{4}$, \\ M. Faruque ${ }^{5}$, Mir Jamiluddin ${ }^{5}$, ME Hoque ${ }^{6}$, KMHS Sirajul Haque ${ }^{1}$, Md. Harisul Hoque ${ }^{1}$ \\ ${ }^{1}$ Department of Cardiology, Bangabandhu Sheikh Mujib Medical University, (BSMMU), Dhaka \\ ${ }^{2}$ Anwer Khan Modern Medical College, Dhaka \\ ${ }^{3}$ Department of Anatomy, Bangladesh Medical College, Dhaka. \\ ${ }^{4}$ Department of Gynecology \& Obstetrics, Bangabandhu Sheikh Mujib Medical University, (BSMMU), Dhaka \\ ${ }^{5}$ Department of Cardiology, National Institute of Cardiovascular Diseases (NICVD), Dhaka. \\ ${ }^{6}$ Consultant, Sadar Hospital, Pirojpur. \\ Address for Correspondence \\ Professor Sajal Krishna Banerjee, Professor, Department of Cardiology, \\ Bangabandhu Sheikh Mujib Medical University, Shahbag, Dhaka. \\ e-mail : drsajalk2003@yahoo.com
}

\begin{abstract}
Clinicians continue to face the challenges of identifying and treating the idiopathic dilated cardiomyopathy to improve symptoms and survival. A study on idiopathic dilated cardiomyopathy was done in the Department of Cardiology, University Cardiac Center, Bangabandhu Sheikh Mujib Medical University, Dhaka, from January 2004 to December 2009. The aim of this study was to examine clinical profile of patients with idiopathic dilated cardiomyopathy. The age range was 18 to 65 years and 70\% subjects were male. Most common symptom was dyspnea (86\%) and cough (75\%). 75\% subjects had sinus tachycardia, $42 \%$ had ventricular ectopics and $40 \%$ had left bundle branch block. Mean diastolic dimension was $60 \pm 9$ mm, ejection fraction was $28 \pm 8 \%$, left atrial dimension was $40 \pm 6 \mathrm{~mm}$ and $36 \%$ were having mitral regurgitation. Left ventricular failure $(75 \%)$ and various type of arrhythmias $(62 \%)$ were the main complications. $8 \%$ subjects were died during hospital stay. Hence the clinical presentation of idiopathic dilated cardiomyopathy varies from patient to patient, but most patients present later, i.e. at some point in the spectrum of heart failure.
\end{abstract}

Key words: Idiopathic dilated cardiomyopathy, left ventricular failure, ventricular ectopics.

\section{Introduction}

Idiopathic dilated cardiomyopathy (IDC) is a primary myocardial disease of unknown cause characterized by left ventricular or biventricular dilatation and impaired myocardial contractility. ${ }^{1}$ Idiopathic Dilated cardiomyopathy (IDC) is much more common than the other major forms of cardiomyopathy (hypertrophic, restrictive and arrhythmogenic right ventricular cardiomyopathy). It is a heterogeneous disease characterized by ventricular and sometimes atrial dilatation, with normal or reduced wall thickness, eventually leading to varying degrees of impaired systolic function. The clinical picture at the time of diagnosis can vary widely from patient to patient; some have no symptoms, whereas others have progressive refractory heart failure. Depending on the diagnostic criteria used, the reported annual incidence varies between 5 and 8 cases per 100,000 population. $^{2-5}$

Males have a 2.5-fold increase in risk, as compared with females, that is unexplained by socioeconomic factors, alcohol intake, or other variables. ${ }^{2,6}$ Convincing associations have been reported between IDC and hypertension, the use of beta-adrenergic agonists, and moderate alcohol consumption. 6,7 Since cardiac dilatation and dysfunction may result from a variety of acquired or hereditary disorders, the differentiation of idiopathic from secondary and potentially reversible forms of myocardial disease has important prognostic and therapeutic implications. The challenge is to identify and treat the known and treatable causes of dilated cardiomyopathy early enough to improve symptoms and survival. Here we describe certain clinical aspects in 100 patients fulfilling the rigorous clinical criteria of IDC.

\section{Materials and Methods}

This prospective observational study was carried out in the Department of Cardiology, University Cardiac Center, Bangabandhu Sheikh Mujib Medical University, Dhaka, from January 2004 to December 2009. Total 100 consecutive patients with chronic total fulfilling the criteria of Idiopathic dilated cardiomyopathy were studied. Inclusion criteria for the diagnosis of IDC was, Ejection fraction of the left ventricle $<45 \%$ and/or fractional shortening $<25 \%$ ( $>2$ 
SD below the mean), as ascertained by echocardiography, radionuclide scanning, or angiography Left-ventricular enddiastolic diameter $>117 \%$ of the predicted value corrected for age and body surface area, which corresponds to $2 \mathrm{SD}$ above the predicted normal limit $\pm 5 \%$. Patients were excluded from the study if they have one or more of the following; systemic hypertension ( $>160 / 100 \mathrm{~mm} \mathrm{Hg}$ ), coronary artery disease (>50\% in one or more major branches), chronic excess alcohol (>40 g/day in women, $>80 \mathrm{~g} /$ day in men for more than 5 years after 6-month abstinence, systemic disease known to cause dilated cardiomyopathy, pericardial diseases, congenital heart disease, valvular heart diseases, cor pulmonale and rapid, sustained supraventricular tachycardia. Detailed inform consent from the patients and ethical permission from the concerned authorities were taken. Clinical diagnosis, investigation reports and complication were recorded.

\section{Statistical analysis}

Statistical analysis was done by SPSS (Statistical Package for Social Science) software for windows version 12.0. Data were expressed in number, percent or mean $\pm \mathrm{SD}$ as appropriate.

\section{Results}

The baseline clinical characteristics of 100 patients with IDC are listed in (Table 1). The age ranged from 18 years to 65 years. Most of the patiens were in the age group of (26-40 years). $70 \%$ were male and $30 \%$ were female. The male:female was 2.33:1. Most of the patients were presented with dyspnea (86\%) followed by cough $(75 \%)$.

Table 1. Baseline characteristics and clinical presentation of the patients $(\mathrm{N}=100)$

\begin{tabular}{|c|c|c|}
\hline Varlables & Numbers & Percent (\%) \\
\hline \multicolumn{3}{|l|}{ Age (in years) } \\
\hline (ís-25 yrars) & 20 & 20 \\
\hline (26-40 yenrs) & 40 & 40 \\
\hline ( 41.55 years) & 25 & 25 \\
\hline ( $96-65$ years) & 15 & 15 \\
\hline \multicolumn{3}{|l|}{ (a) } \\
\hline Male & $\pi$ & 70 \\
\hline Fumalo & 30 & 30 \\
\hline Dyspoca & 86 & 86 \\
\hline Palpitation & 30 & 30 \\
\hline Chest pain & 20 & 20 \\
\hline Cough & 75 & 75 \\
\hline Swelling of legs & 50 & 50 \\
\hline Asymptomatic & 12 & 12 \\
\hline
\end{tabular}

All the data are in total number and percent.

Electrocardiographic observation during the study period revealed different types of non sustained arrhythmias and conduction disturbances together with chamber enlargement (Table 2).
Table 2. Electrocardiographic findings of the patients ( $\mathrm{N}=\mathbf{1 0 0})$.

\begin{tabular}{|c|c|c|}
\hline Variables & Numbers & Percent (\%) \\
\hline Sinus tachycardia & 75 & 79 \\
\hline Left atrial enlargement & 30 & 30 \\
\hline Left bundle branch block & 40 & 40 \\
\hline $\begin{array}{l}\text { Poor progression of } \mathrm{R} \text { in pre- } \\
\text { condial leads }\end{array}$ & 20 & 20 \\
\hline ST- $\mathrm{T}$ changes & 25 & 25 \\
\hline Atrial premature complexes & 12 & 12 \\
\hline Atrial fibrillation (non sustained) & 30 & 30 \\
\hline $\begin{array}{l}\text { Supraventricular tachycardia (non } \\
\text { suatained) }\end{array}$ & 8 & 8 \\
\hline Ventricular ectopic bests & 42 & 42 \\
\hline $\begin{array}{l}\text { Ventricular tachycardia (non } \\
\text { pretained) }\end{array}$ & 5 & 5 \\
\hline Low voltage & 15 & 15 \\
\hline Left axis deviation & 40 & 40 \\
\hline
\end{tabular}

All the data are in total number and percent

A two-dimensional echocardiographic evaluation was performed according to the standards of American Society of Echocardiography in all patients using a commercially available ultrasonic system (Siemens Acuson CV70). Technically satisfactory echocardiographic images were obtained in all patients. To obtain a stable baseline hemodynamic state, subjects rested in the supine position for $10 \mathrm{~min}$ before undergoing the imaging examination. LV fractional shortening was calculated by dividing the difference between the end-diastolic and the end-systolic dimensions by the end-diastolic dimension. LV volumes were measured at end-systole and end-diastole using Ticholz and modified Simpson method using parasternal long axis, short axis, apical four-chamber and apical long-axis views.

Table 3. Echocardiographic findings of the patients ( $\mathrm{N}=\mathbf{1 0 0})$.

\begin{tabular}{|c|c|c|}
\hline Parameters & $\begin{array}{c}\text { Number' } \\
\text { Meann+8D }\end{array}$ & Percent \\
\hline Diestolic dimension, mm & $60 \pm 9$ & . \\
\hline Systolio dimansion, mm & $50 \pm 10$ & . \\
\hline FS, \% & $14 \pm 4$ & . \\
\hline $\mathrm{EF}, \%$ & $28 \pm 8$ & - \\
\hline PW diastolic/systolie thiekness, mm & $8 \pm 2 / 10 \pm 2$ & - \\
\hline IVS disstolic/systolic thickness, mm & $8+1 / 10 \pm 2$ & . \\
\hline LA diameter, mm & $40 \pm 6$ & . \\
\hline RV diastolis diamoter, mm & $22 \pm 4$ & . \\
\hline Mitral regurgitation & 36 & 36 \\
\hline Puricardial effusion & 12 & 12 \\
\hline Left Ventricular thrombus & 08 & 08 \\
\hline Pulmonary hypartension & 35 & 35 \\
\hline Left Ventrieular systolie dysfunction & 100 & 100 \\
\hline
\end{tabular}

All the data are in total number, percent and mean \pm standard deviation. FSfractional shortening, EF-ejection fraction, PW-LV posterior wall, IVSinterventrcular septum, LA-left atrium. 
The LV EF was calculated by dividing the difference between the end-diastolic and the end-systolic volumes by the enddiastolic volume. All the patients had left ventricular systolic dysfunction, mitral regurgitation (36\%), pericardial effusion (12\%) and pulmonary hypertension (35\%).

Left ventricular failure with pulmonary edema $(75 \%)$ was the most common complication followed by different types of arrhythmias (62\%). Eight patients (8) died during the hospital stay due to heart failure and sudden death (Table 4).

Table 4. Complications during hospital stay among the patients $(\mathrm{N}=100)$.

\begin{tabular}{lll}
\hline Parameters & Number & Pereent \\
\hline Arrhythmias & 62 & 62 \\
LVF with palmonary edema & 75 & 75 \\
Throenbo-embolism & 05 & 05 \\
Death & 08 & 08 \\
\hline
\end{tabular}

All the data are in total number and percent. LVF-left ventricular failure.

\section{Discussion}

Though the term idiopathic dilated cardiomyopathy is a convenient description for a syndrome resulting from cardiac muscle dysfunction it does not describe a homogenous entity. Even this broad definition is a misnomer because the same cardiac dysfunction can occur in the absence of dilatation $^{8}$ or be confined to one ventricle. ${ }^{9}$ With growth of knowledge and techniques, specific etiological agents were identified and reclassified as distinct disorders. The various risk factors resemble those noted in other countries. The preponderance of men ${ }^{10-12}$ and those in the lower socioeconomic classes ${ }^{13,14}$ has been reported by others. Of other factors thought to be of etiological importance, alcohol is the most commonly reported. Some authorities consider that alcoholic cardiomyopathy is a specific entity which should not be classified as idiopathic dilated cardiomyopathy. In this study we also found the male preponderance together with low socio-economic status how ever in this study none of the patient was alcoholic. The increased frequency of dilated cardiomyopathy in low socioeconomic classes has led to the suggestion that it may be related to faulty nutrition. In this study we were not able to explore much about nutritional status and some specific diagnostic tests e.g. transketolase test.

Both this study and previous work in this area are limited by the lack of specific diagnostic criteria. Since the report of the World Health Organization/International Society and Federation of Cardiology Task Force, ${ }^{1}$ the term "cardiomyopathy" has been reserved for heart muscle disorders of unknown cause, which may be classified as dilated, hypertrophic, or restrictive, according to their anatomic and functional features.
Heart muscle disease of known cause; that is, that due to systemic or pulmonary hypertension, coronary artery disease, valvular or congenital heart disease, infective or metabolic causes, and those associated with systemic disorders are specifically excluded. Thus, the diagnosis of idiopathic cardiomyopathy is primarily one of exclusion supported by a combination of clinical features, many of which are nonspecific. In the absence of a specific clinical finding or diagnostic test, there are, inevitably, problems in diagnosis and classification.

The criteria for inclusion and exclusion used in this study may not be universally acceptable. A review of the literature shows, however, that specific and detailed criteria are difficult to find or are non-existent. It was therefore necessary to formulate such criteria, which we consider are sufficiently precise for comparison. There are several reasons why our figures may appear low. Firstly, we did not investigate a population but only assessed the available information in patients who were admitted in a university hospital for the purpose of better treatment. Thus we are faced with all the problems of a single center study: how often was a correct diagnosis of cardiomyopathy missed? Were all the patients with cardiomyopathy referred? Secondly, and most importantly, our criteria may be rigid that a suspicion of any specific heart muscle disorder (for example) resulted in exclusion from the study. Dilated cardiomyopathy is thought to be a condition of multifactorial origin. ${ }^{15}$ In particular; (viral) myocarditis may be the cause of a proportion of cases probably by way of an immunological pathogenesis. The problem is, however, that there is a large grey zone of overlapping conditions: chronic myocarditis, healed myocarditis, sequelae of myocarditis, and dilated cardiomyopathy. It should be emphasized that our approach was to exclude patients in whom a diagnosis of present or past myocarditis was suspected. We made every possible effort to exclude coronary heart disease, which may mimic cardiomyopathy clinically (especially dilated cardiomyopathy). However coronary angiogram the gold standard for the diagnosis of coronary artery disease was not possible in all patients.

The present study shows the minimum figures for the occurrence of symptomatic cardiomyopathy in our population probably the tip of iceberg. A prospective study would undoubtedly show a higher frequency. More precise data would, however, require a population study based on an echocardiographic evaluation with subsequent coronary angiography and histological examination of biopsy specimens in cases suspected of dilated cardiomyopathy. A study of this design is not possible for practical and ethical reasons, and the many problems of defining early cases would still remain. A definition of disease including the terms unknown/idiopathic is not satisfactory but is unfortunately 
often realistic. Increased insight and experience in determining the incidence of such disorders will naturally reduce the number of cases. Treatment of IDC is aimed primarily at alleviating symptoms of congestive heart failure and preventing sudden death. Although many patients benefit from it, drug therapy does not treat the underlying cause of the cardiac dysfunction nor necessarily arrest progression of the disease. Cardiac transplantation may offer the only hope of improved quality of life and increased survival in patients with end-stage heart muscle disease due to IDC.

\section{Conclusion}

This study was a small, single center study however a population based large prospective study will be more accurate and will reflect the true picture and magnitude of the problem.

\section{References}

1. Report of the WHO/ISFC task force on the definition and classification of cardiomyopathies. Br Heart J 1980;44:67273

2. Gillum RF. Idiopathic cardiomyopathy in the United States, 1970-1982. Am Heart J 1986;111:752-55

3. Bagger JP, Baandrup U, Rasmussen K, Moller M, Vesterlund T. Cardiomyopathy in western Denmark. Br Heart $J$ 1984;52:327-31

4. Williams DG, Olsen EGJ. Prevalence of overt dilated cardiomyopathy in two regions of England. Br Heart $J$ 1985;54:153-55

5. Codd MB, Sugrue DD, Gersh BJ, Melton LJ III. Epidemiology of idiopathic dilated and hypertrophic car- diomyopathy: a population-based study in Olmsted County, Minnesota, 1975-1984. Circulation 1989;80:564-72

6. Coughlin SS, Szklo M, Baughman K, Pearson TA. The epidemiology of idiopathic dilated cardiomyopathy in a biracial community. Am J Epidemiol 1990;131:48-56

7. Hartz AJ, Anderson AJ, Brooks HL, Manley JC, Parent GT, Barboriak JJ. The association of smoking with cardiomyopathy. N Engl J Med 1984;311:1201-06

8. Keren A, Billingham ME, Weintraub D, Stinson EB, Popp RL. Mildly dilated congestive cardiomyopathy. Circulation 1985;72:302-04

9. Fitchett DH, Sugrue DD, MacArthur CG, Oakley CM. Right ventricular dilated cardiomyopathy. Br Heart $J$ 1984;51: 25-29

10. Segal JP, Stapleton JF, McClellan JR, Waller BF, Harvey WP. Idiopathic cardiomyopathy: clinical features, prognosis and therapy. Curr Probl Cardiol 1978;3:39-49

11. Fuster V, Gersh BJ, Giuliani ER, Tajik AJ, Brandenburg RO, Frye RL. The natural history of dilated cardiomyopathy. Am J Cardiol 1981;47:525-31

12. Schwarz F, Mall G, Zebe H, Schmitzer E, Manthey J, Scheurlen H, Kubler W.Determinants of survival in patients with congestive cardiomyopathy: quantitative morphologic findings and left ventricular hemodynamics. Circulation 1984;70:923-28

13. Johnson RA, Palacios I. Dilated cardiomyopathies of the adult. Part 1. N Engl J Med 1982;307:1051-58

14. Hill KR, Still WJS, McKinney B. Jamaican cardiomyopathy. Br Heart J 1967;29:594-601

15. Goodwin JF. Introduction, problems and aims of the multicentre research project. Postgrad Med J 1978; 54:431-32 